\title{
Soft Palate Pleomorphic Adenoma
}

National Cancer Institute

\section{Source}

National Cancer Institute. Soft Palate Pleomorphic Adenoma. NCI Thesaurus. Code C6211.

A benign, slow-growing and painless neoplasm that arises from the minor salivary glands in the soft palate. It is composed of cells that demonstrate both epithelial and mesenchymal differentiation. 